\title{
AN INTEGRATED APPROACH FOR DESIGN AND MANUFACTURE OF PLASTIC PRODUCTS
}

UDC: 658.512 .2

Original scientific paper

https://doi.org/10.18485/aeletters.2019.4.1.1

\author{
Ivan Matin ${ }^{1}$, Djordje Vukelic ${ }^{1}$, Miodrag Hadzistevic ${ }^{1}$, Branko Strbac ${ }^{1}$, Dejan Lukic ${ }^{1}$ \\ ${ }^{1}$ University of Novi Sad, Faculty of Technical Sciences, Novi Sad, Serbia
}

\begin{abstract}
:
The aim of this paper is to present an integrated design procedure for plastic part development and manufacture. Reverse engineering (RE), reengineering ( $\mathrm{ReE}$ ) and mold design have been incorporated to infuse agile characteristics in the proposed design and development process. The integration of RE and ReE presented in this paper accelerate the design process and provide information necessary for complete injection molding process of plastic parts. The purpose is to create a new object geometrically similar to the existing object. The new object must have better mechanical properties and more favorable geometry from the standpoint of mold ability. This paper also, describes a methodology for quality geometry check of the manufactured part that is need for verified the used integrated CAD/CAE technologies.
\end{abstract}

\section{ARTICLE HISTORY}

Received: 16.01.2019.

Accepted: 01.03.2019.

Available: 31.03.2019.

\section{KEYWORDS}

mold design, reverse

engineering, re-engineering,

injection molding simulation

\section{INTRODUCTION}

Reverse engineering (RE) is a kind of engineering, which takes advantage of an already created object. The reconstruction of digital geometric models of physical objects, usually indicated as RE in the CAD field, has been extensively studied in recent years, due to the development and spreading of 3D scanning technologies and the increase in number of appropriate applications [1-6]. RE in fact, exploit 3D data acquired on the physical object and describing its surfaces as starting point for the reconstruction framework [1,2,7]. Many researchers have contributed to the ReE area demonstrating its usefulness to leverage the product design and development process. Chang et al. $[8,9]$ proposed an integrated testbed approach for development of the integrated components. The authors performed topology combined with boundary smoothing and geometry reconstruction operations in order to improve material characteristics in the product design process. Garcia et al. [10] examined a FEM analyses together with algorithms for shape design to minimize stress and weight of designed parts. The other authors have used CAD and CAE to correct the design. The created CAD model is modified further to get an optimal product design. This process is defined as systematic evaluation of a product with the purpose of replication, which involves either direct copies when no design and manufacturing documentation exists, or improvement of an existing design. In addition, RE subject area has been widely recognized as being a substantial step in the product development process. Other applications of RE include recovery of damaged or broken part, the design of a new component and a simulation model $[1,2,7]$. SoviljNikic et al. [11] measured roughness parameters of surfaces of the hob milling tools using the measuring device "MahrSurf PS1". Same device and same method were used for surface measurement of the manufactured part presented in this scientific paper. Deng et al. [12] created feature-based CAD/CAE integration model for injection molded product design. The design case illustrated the bidirectional integration process. 
Zhou et al. [13] and developed a virtual injection molding system based on numerical simulation. The authors presented a desktop-based, low-cost, and independent virtual injection molded system, which was implemented using the advanced techniques such as virtual reality, finite element method (FEM), numerical simulation, and scientific visualization.

Many research studies are indicating that by integrating $\mathrm{RE}, \mathrm{ReE}$ and manufacture principles in product design process, companies can achieve high rate in manufacturing [1-8, 12, 14, 15, 16-19].

Having this in mind, it can be concluded that it is essential to build integrated design for revised plastic parts. The segment of this approach is to combine RE, ReE and mold design for model reconstruction using PTC Creo Parametric and Pro/Mechanica software. The purpose is to create a new object geometrically similar to the existing object. The new object must have better mechanical properties. The next segment is to prepare correct CAD/CAE model of the reconstructed part that is necessary for mold design and injection molding simulation process. The RE workflow involves the sequential development of discrete model for data acquisition, data capture, data editing and data fitting phases. These include physical object, point cloud model, mesh model, surface model, and digitized parametric CAD model. The ReE workflow also involves development of a discrete model to detect high stressed regions and simulation model to determine injection molding parameters.

\section{METHODOLOGY}

The physical object selected for demonstration of the proposed RE and ReE workflow is forced for retrieval from design and manufacturing process. In addition, the damaged part geometry needs to be recovered in order to improve the part functionality and to overcome the design flaws in the existing design. Physical object, which is used in this case study, is a broken shower gel cover, where some of its mechanical properties (especially stress) do not meet acceptable values. The new object must have acceptable geometry from the standpoint of mold ability.

Integrated design flow for plastic part development consists of RE, ReE and mold design. An Integrated design flow for plastic part development is indicated in Fig.1.

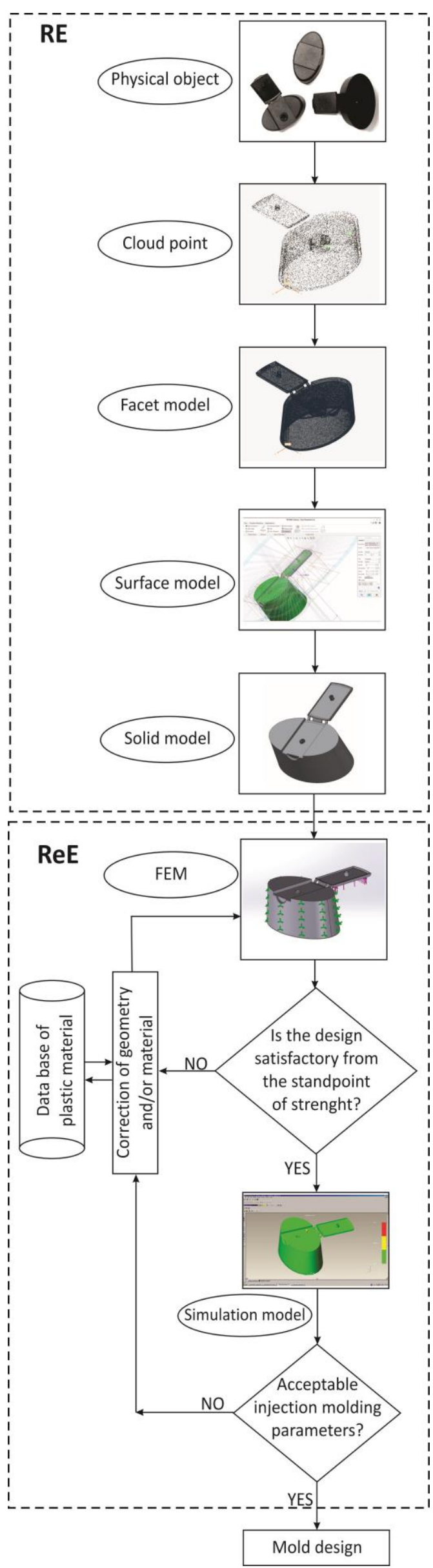

Fig. 1. Integrated design flow for plastic part development 
The compact class 3D scanner ATOS converts the physical object into point cloud using triple scan method. The ATOS systems return full-field data about deviations between the actual 3D coordinates and the CAD data. As this measuring data contains the information, in addition to the surface deviations from the CAD, the software also derives detailed information such as geometric dimensions and tolerances and, trimming or hole positions. The accuracy of optical measuring systems is based on state-of-the-art optoelectronics, precise image processing, and algorithms, ensured by precision standards and an automated calibration procedure. The RE consists of few operations such are scanning, data acquisition, surface modeling, and conventional solid modeling. Then conventional solid model was ready for meshing using FEM in Pro/Mechanica software. Studying or analyzing a phenomenon with FEM is initiated to as a finite element analysis (FEA). Authors modified some geometry specification and changed plastic material of the model, and then made satisfactory ReE design of the model ready for injection molding process simulation and mold design. RE and ReE activities are data acquisition, point cloud creation, model reconstruction and patch design, solidify procedure using automatic options, stress simulation (Fig.1).

The FEM model can be directly imported into injection molding simulation software such as Pro/Plastic Advisor, MoldFlow or Moldex 3D without loss of the semantics and topological information inherent in feature-based or facet representations. Injection molding parameters are the folowing:

- Flow length,

- location of gate/gates,

- number of gates

- mold temperature,

- melt temperature,

- injection pressure,

- maximal injection molding machine pressure,

- part thickness,

- cooling time,

- ejection temperature and

- part material.

In addition to the previously mentioned parameters of injection molding, the Plastic Advisor software determine injection molding pressure, shear stress distribution, temperature distribution on the surface of the simulation model, the quality of filling of a simulation model, the quality of a simulation model from the standpoint of cooling.

Plastic Advisor provides molding process dynamic simulation and its technological effectiveness analysis on basis of Moldflow software. Also, is intended for mold base molding and cooling time determination, potential problem areas detection. Optimal gate location in the simulation model is indicated in Fig.2.

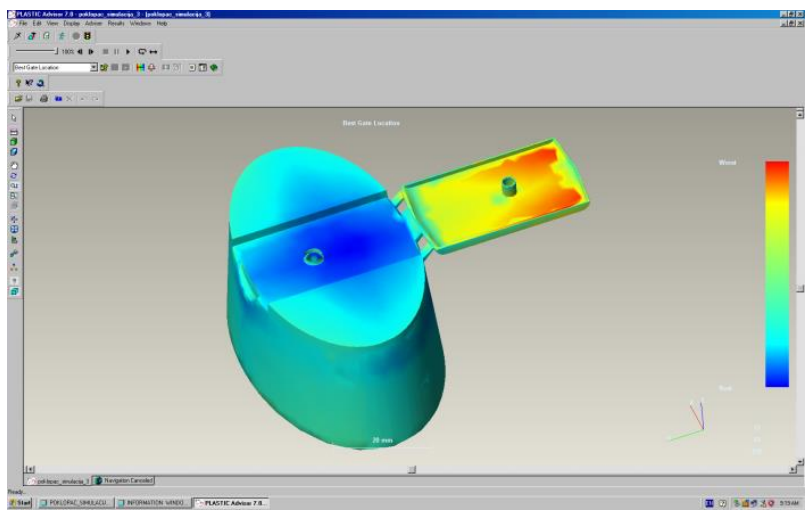

Fig.2. Optimal gate location in the simulation model

Dark blue regions represent the optimal gate location for setting gate system in the simulation model as indicated in Fig.2.

The "Confidence of fill" analyze is very important for quality prediction of the part. The results of this analyze is presented in Fig.3.

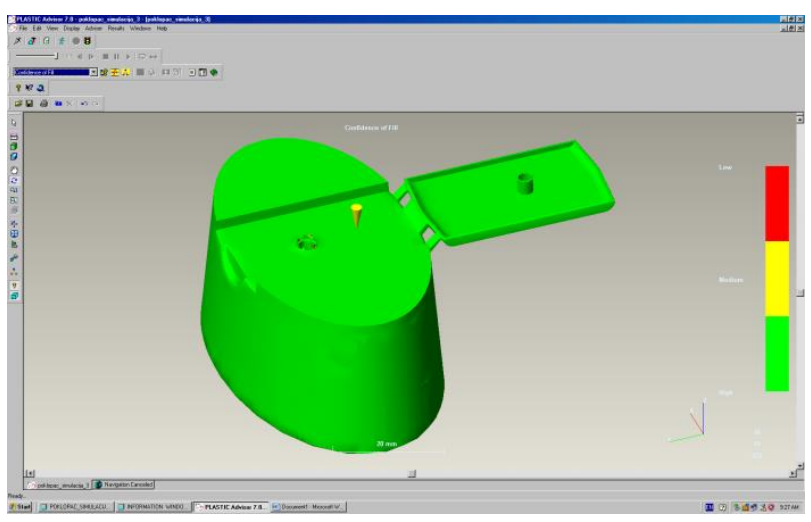

Fig. 3. Fill quality of the simulation model

The simulation model is completely filled. The all regions are green that means that the chosen injection molding parameters are fully acceptable.

The PTC Creo is used for core and cavity design and final mold assembly design. This software uses additional software tools for automation creating core and cavity from simulation model including shrinkage factor of plastics material and automation splitting mold volumes of the fixed and movable plates. The specialized CAE software "SAPA" used for determining of dimensions of core 
and cavity of the mold plate. This software used for standard mold plate/assembly selection. The designed mold assembly is indicated in Fig.4.

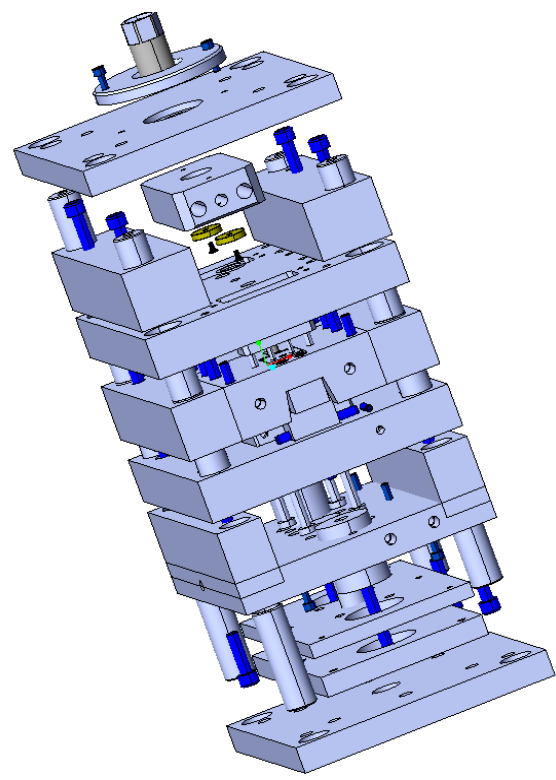

Fig. 4. 3D model of the final mold assembly

The drawing of the final mold assembly is indicated in Fig.5.

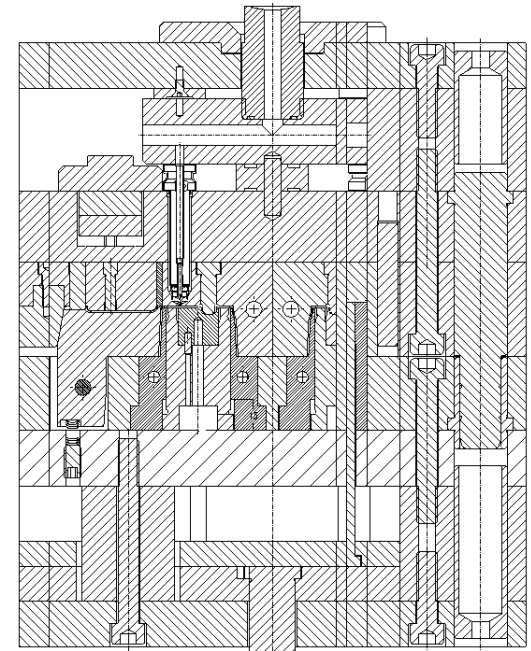

Fig.5. Cross section of the final mold assembly

The mold assembly consists of standard plates "Meusburger", "HASCO", and special own manufactured plates (Fig.4, Fig.5.). The U-layout circular cross-section waterline channels solve the cooling of the mold (Fig.4, Fig.5.). The cooling medium is a compound composed of $75 \%$ water and $25 \%$ ethyl glycol.

\section{THE QUALITY CHECK OF THE MANUFACTURED PART}

CAD Inspection of the part and measure of arithmetic mean roughness of the surfaces are need to quality check.
The arithmetic mean roughness values were determined with constant Gauss low-pass filter (cut-off length of $2.5 \mathrm{~mm}$ ) according to ISO 4287 using Mahr MARSURF PS1. The plastic cover derived roughness grade number N6 to N7. The arithmetic mean roughness values measured on the part are from $1.612 \mu \mathrm{m}$ to $2.011 \mu \mathrm{m}$.

The dimensional deviation between the designed CAD model and manufactured part was determined using the coordinate measuring machine Contura G2 and GOM Inspect software. The dimensional deviation between the simulation model and the manufactured part is $0.011 \mathrm{~mm}$.

\section{CONCLUSION}

The methodology indicates that complete RE and ReE works have satisfactory performance, which can improve the quality of a part. The objective of this research was to develop and manufacture the correct shower gel cover with acceptable material and geometry. The described working modeling process is feature-based, objectoriented, and parametric. An integration of $\mathrm{RE}, \mathrm{ReE}$ and mold design tools displays a good affinity in achieving satisfying characteristics in the contemporary product design and injection molding process.

RE and CAD systems were instrumental in the development of parametric CAD model, which was then carried iteratively to testing in a CAE environment for simulation of stress regions in order to enhance geometrical modification.

The material and geometry specifications are correct. The dimensional deviation and arithmetic mean roughness values are acceptable, that means the part is of sufficient quality.

The proposed procedure allows full control over CAD/CAE feature parameters, which enables convenient mold selection and modification.

Future improvements may include the other scanning procedures, such as close-range photogrammetric method with the application of the specialized software for image processing.

\section{ACKNOWLEDGEMENTS}

This work was supported by the projects no. TR35020 and TR35025, founded by the Ministry of Education, Science and Technological Development of Republic of Serbia. 


\section{REFERENCES}

[1] A. Fahraz, B.V. Chowdary, L. Gonzales, An integrated design approach for rapid product development: A case study through application of reverse engineering, reengineering and fast prototyping tools. Journal of Engineering, Design and Technology, 11 (2), 2013: 178-189.

https://doi.org/10.1108/JEDT-06-2011-0042

[2] I. Matin., D. Vukelic., M. Hadzistevic., B. Strbac, Z., Santosi., D. Lukic, An integrated design approach for plastic part development. $13^{\text {th }}$ International Scientific Conference MMA, Novi Sad, Serbia, September 28-29, 2018.

[3] M. Buonamici, M. Carfagni., R. Furferi, L. Governi, A. Lapini, F. Volpe, Reverse engineering of mechanical parts: A templatebased approach. Journal of Computational Design and Engineering, 5 (2), 2018: 145-159.

https://doi.org/10.1016/i.jcde.2017.11.009

[4] A. Voicu, I.G. Gheorghe, L.L. Badita., A. Cirstoiu, 3D Measuring of complex automotive parts by multiple laser scanning. Applied Mechanics and Materials, 371, 2013: 519-523.

https://doi.org/10.4028/www.scientific.net/AMM.371.519

[5] J. Wang, D. Gu, Z. Gao, Z. Yu, C. Tan, L. Zhou, Feature-based solid model reconstruction. Journal of Computing and Information Science in Engineering, 13 (1), 2013: 211-223.

[6] J. Wang, D. Gu, Z. Yu, C. Tan, L. Zhou, A framework for 3D model reconstruction in reverse engineering. Computers and Industrial Engineering, 63, 2012: 1189-1200.

https://doi.org/10.1016/i.cie.2012.07.009

[7] B.V. Chowdary, A. De Noon, F. Ali, C. Imbert, An investigation for improvement of the 3Ddigitization process: a reverse engineering approach. Journal of Manufacturing Technology Management, 22 (1), 2011: 131147.

https://doi.org/10.1108/17410381111099842

[8] K.H. Chang, C. Chen, 3D shape engineering and design parameterization. Computer-Aided Design and Applications, 8 (5), 2011: 681-692.

https://doi.org/10.3722/cadaps.2011.681-692

[9] K.H. Chang, Z. Siddique, M. Edke, Z. Chen, An integrated testbed for reverse engineering of aging systems and components. ComputerAided Design and Applications, 3 (1-4), 2006: 21-30.

https://doi.org/10.1080/16864360.2006.10738438

[10] M.J. Garcia, P. Boulanger, M. Henau, Structural optimization of as-built parts using reverse engineering and evolution strategies. Structural and Multidisciplinary Optimization, 35 (6), 2008: 541-550.

https://doi.org/10.1007/s00158-007-0122-6

[11] I. Sovilj-Nikic, S. Sovilj-Nikic, B. Sovilj, I. Samardzic, D. Kozak, V. Blanusa, Analysis of roughness parameters of lateral back surfaces of model hob milling tools during cylindrical gear cutting. Applied Engineering Letters, 3 (2), 2018: 63-71.

https://doi.org/10.18485/aeletters.2018.3.2.3

[12] Y.M. Deng, G.A. Britton, Y.C. Lam, Y.S. Ma, Feature-based CAD/CAE integration model for injection-moulded product design. International Journal of Production Research, 40 (15), 2002: 3737-3750.

https://doi.org/10.1080/00207540210141643

[13] H. Zhou, S. Shi, B. Ma, A virtual injection molding system based on numerical simulation. International Journal of Advanced Manufacturing Technology, 40 (3-4), 2009: 297-306.

https://doi.org/10.1007/s00170-007-1332-1

[14] J. Zhou, J. Li, Y. Hu, J. Yang, K. Cheng, Plastic mold design of top-cover of out-shell of mouse based on CAE. Advanced in Control Engineering and Information Science, Procedia Engineering, 15, 2011: 4441-4445.

https://doi.org/10.1016/i.proeng.2011.08.834

[15] I. Matin., M. Hadzistevic., J. Hodolic, D. Vukelic, D. Lukic, A CAD/CAE-integrated injection mold design system for plastic products. International Journal of Advanced Manufacturing Technology, 63, 2012: 595-607. https://doi.org/10.1007/s00170-012-3926-5

[16] M. Hadzistevic, I. Matin, J. Hodolic, D. Vukelic, S. Vukmirovic, D. Godec, B. Nedic, Rule base reasoning in the knowledge-based mould design system. Tehnicki vjesnik - Technical Gazette, 21 (5), 2014: 1330-3651.

[17] I. Matin, M. Hadzistevic, D. Vukelic, M. Milutinovic, R. Golebski, Application of numerical simulation of injection molding of medical accessory. Journal for technology of plasticity, 41 (1), 2016: 47-55.

[18] Y. Lou, H. Jiang, X. Ruan, Development of an Integrated knowledge-based system for mold base design, Journal of Materials Processing Technology, 150 (1), 2004: 194-199.

https://doi.org/10.1016/i.jmatprotec.2004.01.037

[19] J. Hodolic, I. Matin, M. Stevic, D. Vukelic, Development of Integrated CAD/CAE System for Mold Design for Plastic Injection Molding, Materiale Plastice, 46 (3), 2009: 236-242. 